\title{
Effects of Gaseous Sulfide on the Reduction of Iron Oxide Pellets*
}

\section{By Rokurō KUWANO,** Takao OKU ${ }^{* * *}$ and Yōichi ONO**}

\begin{abstract}
Synopsis
Effects of addition of $5 \%$ of gaseous sulfide on the rate of reduction of iron oxide pellets were studied in temperature range of 800 to $1000^{\circ} \mathrm{C}$ with the following results:

(1) The reduction rate was greatly decreased with the additon of COS and $\mathrm{H}_{2} \mathrm{~S}$ respectively to $\mathrm{CO}$ and $\mathrm{H}_{2}$.

(2) Analysis of the reduction rate based on the unreacted-core model and observation of the fractured surface of partially reduced pellets by using a scanning electron microscope and an electron probe microanalyzer demonstrated that the formation of dense $\mathrm{FeS}$ shells offered great resistance to the intraparticle diffusion of reducing gas toward the oxide core, thus greatly retarding the reduction of pellets, and that the partial penetration of the sulfide gas into the oxide core was also responsible to the decrease of reduction rate.
\end{abstract}

\section{Introduction}

Not only sulfur transfer by slag-metal reaction but also sulfur transfer between gaseous sulfides and burden materials have recently been studied by many investigators for better understanding of the behavior of sulfur in a blast furnace, and many papers in connection with gaseous sulfides-burden materials sulfur transfer have been published by Neuhaus et al. and others. ${ }^{1-16)}$ In particular, it is gradually becoming clear that the gaseous sulfides as well as alkalis are concerned in the formation of the softening-melting zone in a blast furnace, so that the behavior of sulfur in the blast furnace has attracted the attention of many investigators. ${ }^{8-13)}$

As part of the studies on the behavior of sulfur in a blast furnace, we reported the experimental results on the absorption rate of sulfur by sponge iron pellets from gaseous sulfides in the previous papers. ${ }^{14,15)}$ Following those papers, we will report the experimental results and their discussion about the effects of gaseous sulfides on the reduction rate of iron oxide pellets in this paper.

\section{Experimental Method}

\section{Samples}

The samples used in the present work were from Keiser pellets. The pellets were once crushed under 325 meshes. Spherical green pellets were made from the powder moistened with about $14 \%$ of water by use of the hand rolling method, and then the green pellets were fired in dry air at $1300^{\circ} \mathrm{C}$ for $60 \mathrm{~min}$. The fired pellet for this experiment was about $4.5 \mathrm{~g}$ in weight, about $13 \mathrm{~mm}$ in diameter, and $15 \pm 1 \%$ in porosity. The chemical composition of the pellet was T.Fe: $64.6 \%, \quad \mathrm{FeO}: 2.27 \%, \mathrm{SiO}_{2}$ : $3.94 \%$, $\mathrm{Al}_{2} \mathrm{O}_{3}: 0.16 \%$, CaO: $0.47 \%$, and $\mathrm{MgO}: 2.76 \%$.

\section{Apparatus}

The schematic experimental apparatus is shown in Fig. 1. The reducing gas used for $\mathrm{CO}$ reduction was produced from $\mathrm{CO}_{2}$ by making it flow through a charcoal layer at $1000{ }^{\circ} \mathrm{C}$. CO-5\% COS mixture for the simultaneous reduction and sulfidation reaction was produced by introducing a fixed mixture of $\mathrm{CO}$ and $\mathrm{SO}_{2}$ through a charcoal layer at $1000{ }^{\circ} \mathrm{C}$. Hydrogen for $\mathrm{H}_{2}$ reduction and $\mathrm{H}_{2}-5 \% \mathrm{H}_{2} \mathrm{~S}$ mixture for the simultaneous reaction were prepared from the respective gases on the market.

In the present work, the change of weight of the pellet during reaction was measured by use of the automatic thermo-balance, which was made in our laboratory by utilizing a strain gauge and was equipped with a quartz reaction tube of $3.4 \mathrm{~cm}$ in diameter.

Since temperature distribution in the reaction tube changed with gas flow rate, the temperature distribution was previously measured under the experimental conditions. The reaction zone could thus be kept at a constant temperature within $10^{\circ} \mathrm{C}$ by using a regulator.

\section{Procedures}

An iron oxide pellet was hung on the thermal balance with a platinum wire and was heated up to the experimental temperature under the nitrogen atmo-

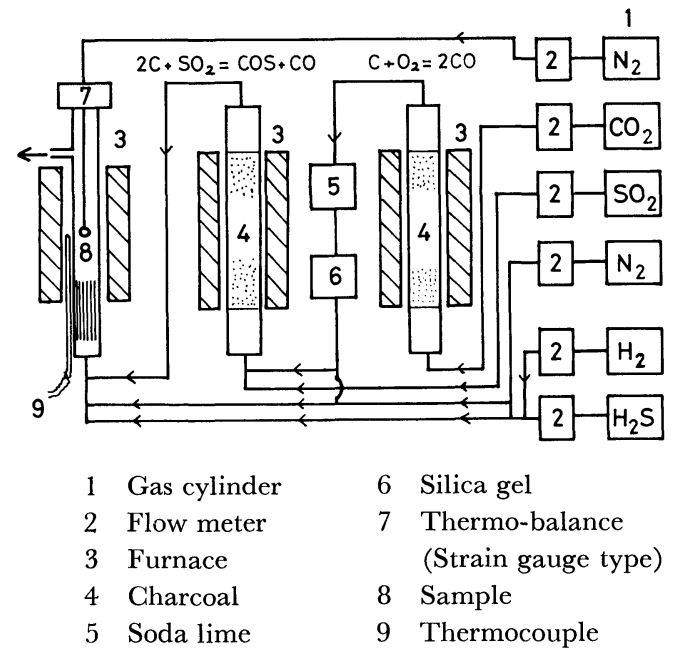

Fig. 1. Schematic diagram of the experimental apparatus.

* Originally published in Tetsu-to-Hagané, 66 (1980), 1622, in Japanese. English version received February 17, 1981.

** Faculty of Engineering, Kyushu University, Hakozaki, Higashi-ku, Fukuoka 812.

*** Formerly Graduate School, Kyushu University. Now at Nihon Radiator Corporation, Minamidai, Nakano-ku, Tokyo 164. 
sphere. Then, the reaction of the pellet with the reaction gas was made to start by replacing nitrogen gas for each reaction gas, and the variation of weight of the pellet during the reaction was measured by use of the thermal balance.

In case of reduction with pure $\mathrm{CO}$ or $\mathrm{H}_{2}$, fractional reduction was calculated from the weight loss of the pellet. In case of the simultaneous reaction, the weight loss of the pellet was a sum of decreased weight by reduction and increased weight by sulfidation. To determine the degree of reduction and that of sulfidation separately, the reaction was stopped at a certain decided time, the pellet was taken out from the reaction tube, and the amount of sulfur in the pellet was analyzed by means of the combustion-volumetric method. The fractional reduction was calculated from the amount of weight loss and that of sulfur in the pellet.

The experiments were made at the respective temperature of $800^{\circ} \mathrm{C}, 900{ }^{\circ} \mathrm{C}$, and $1000^{\circ} \mathrm{C}$ and under the gas flow rate of $2.2 \mathrm{~N} l / \mathrm{min}$ in all cases.

\section{Experimental Results and Discussions}

\section{Fractional Reaction Curves}

Figure 2 shows some examples of weight loss curves, where fractional weight loss of iron oxide pellets, $f_{R}$ for $\mathrm{CO}$ reduction and $f_{R S}$ for the simultaneous reaction with $\mathrm{CO}-5 \% \mathrm{COS}$ are plotted against reaction time. This figure shows a tendency that the weight of pellets hardly changed or increased slightly during the simultaneous reaction, which indicates that the reduction and the sulfidation proceeded simultaneously.

Figure 3 shows the fractional reduction curves for the simultaneous reaction with $\mathrm{CO}-5 \% \mathrm{COS}$ calculated by the method described above, and those for $\mathrm{CO}$ reduction. The figure indicates that the reduction rate for the simultaneous reaction was greatly decreased at each temperature as compared with the reduction rate with pure CO. Moreover, it is noteworthy that the reduction rate for the simultaneous

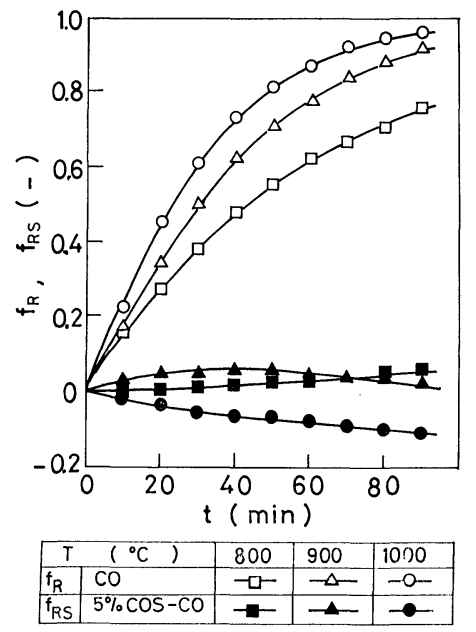

Fig. 2. Fractional weight loss curves during the reduction and the simultaneous reduction and sulfidation reaction. reaction at $1000{ }^{\circ} \mathrm{C}$ was somewhat smaller than that at $900{ }^{\circ} \mathrm{C}$.

Figure 4 shows the fractional reduction curves for the simultaneous reaction with $\mathrm{H}_{2}-5 \% \mathrm{H}_{2} \mathrm{~S}$ in contrast with those for $\mathrm{H}_{2}$ reduction. Also in this case, the reduction rate for the simultaneous reaction was smaller than that for $\mathrm{H}_{2}$ reduction, and the difference in reduction rate showed a remarkable increase as temperature was lowered.

In case of the simultaneous reaction, the fractional sulfidation can also be calculated from the experimental results by the same method as described above. Although the results will not be shown in details in this paper, the results showed that the absorption rate of sulfur was increased with a rise in temperature as it was the case with the sulfur absorption by sponge iron pellets reported in the previous papers. ${ }^{14,15)}$

It seems that one of the causes of the retardation of reduction rate was the reduced partial pressure by the addition of gaseous sulfide, i.e., a decrease of driving force for reduction. In order to investigate this point, the reduction of pellets was tried with $\mathrm{CO}-\mathrm{N}_{2}$ mixture which had been adjusted to approximately the same $\mathrm{CO}$ partial pressure as that of the CO-COS gas described above. Figure 5 represents the fractional reduction curves with $\mathrm{CO}-8 \% \mathrm{~N}_{2}$ and those for reduc-

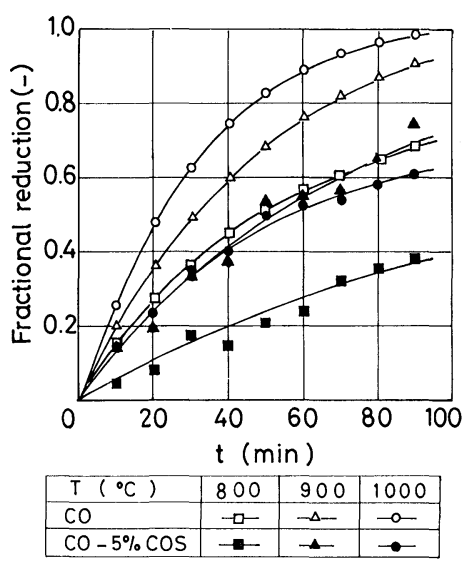

Fig. 3. Fractional reduction curves for $\mathrm{CO}$ reduction and $95 \% \mathrm{CO}-5 \% \mathrm{COS}$ simultaneous reaction of iron oxide pellets.

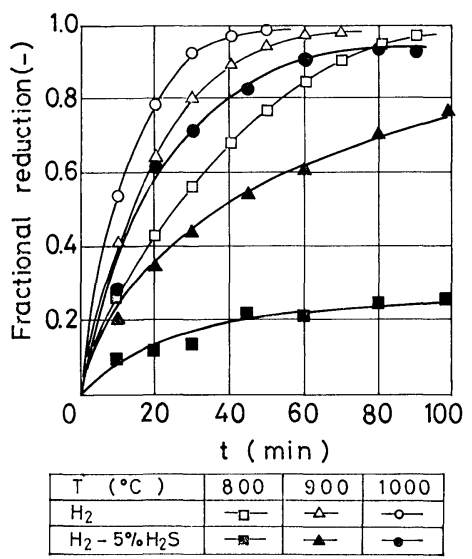

Fig. 4. Fractional reduction curves for $\mathrm{H}_{2}$ reduction and $95 \% \mathrm{H}_{2}-5 \% \mathrm{H}_{2} \mathrm{~S}$ simultaneous reaction of iron oxide pellets. 


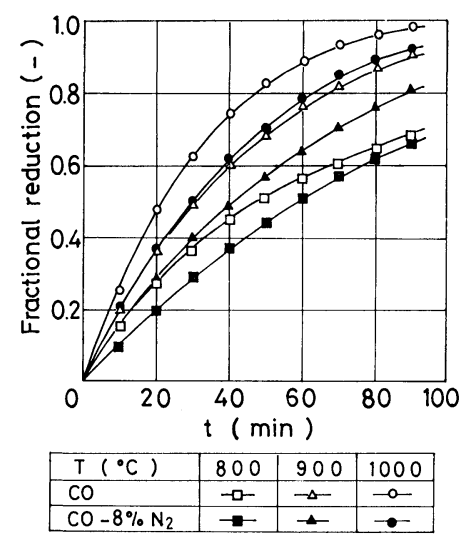

Fig. 5. Comparison of fractional reduction for $\mathrm{CO}$ reduction with fractional reduction for $\mathrm{CO}-\mathrm{N}_{2}$ reduction under reduced $\mathrm{CO}$ partial pressure.

tion with pure CO. In Fig. 6 the fractional reduction curves for the reduction with $\mathrm{CO}-8 \% \mathrm{~N}_{2}$ are shown in contrast with those for the simultaneous reaction with CO-5\%COS. These figures show that the decrease of reduction rate because of the addition of gaseous sulfide was so far greater than that resulting from the reduction in partial pressure of reducing gas. Although the reduced partial pressure of reducing gas was also one of the causes of the retarded reduction rate, its effect was found to be fairly small within the pressure range of this experiment. The results approximately similar to those described above were also found for the reduction with $\mathrm{H}_{2}, \mathrm{H}_{2}-\mathrm{N}_{2}$, and $\mathrm{H}_{2}-\mathrm{H}_{2} \mathrm{~S}$.

\section{Rate Analysis Based on the Unreacted-core Model17)}

If the reaction proceeds according to the unreactedcore model, this reaction process consists of the following three steps; the gas film mass-transfer, the intraparticle diffusion, and the chemical reaction at the interface. The rate equation in which these three steps are considered, can be described by Eq. (1),

$$
\begin{aligned}
\dot{n} & =-4 \pi r_{i}^{2} d_{o} \frac{d r_{i}}{d t} \\
& =\frac{1}{k_{g}+\frac{1}{D_{e}} \cdot \frac{r_{o}\left(r_{o}-r_{i}\right)}{r_{i}}+\frac{1}{k_{r}(1+1 / K)} \cdot\left(\frac{r_{o}}{r_{i}}\right)^{2}}
\end{aligned}
$$

Integrating Eq. (1), and rearranging the resultant equation, we obtain Eq. (2) for the relation between reaction time $t$ and relative thickness $f$ of reacted layer,

$$
\begin{aligned}
& \frac{C_{A b}-C_{A e}}{r_{o} d_{\mathrm{o}}} \cdot \frac{t}{f}-\frac{1}{k_{g}} \cdot \frac{3-3 f+f^{2}}{3} \\
& ={ }^{r_{o}}\left(3 f-2 f^{2}\right)+\frac{1}{k_{r}(1+1 / K)}
\end{aligned}
$$

where,

$$
f=\left(r_{o}-r_{i}\right) / r_{o}=1-(1-F)^{1 / 3} .
$$

Gas film mass-transfer coefficient $k_{g}$ is estimated according to Ranz and Marshall. ${ }^{18)}$

When the values of the left hand side of Eq. (2) calculated from the experimental data are plotted against $\left(3 f-2 f^{2}\right)$, the plot may give a straight line, if

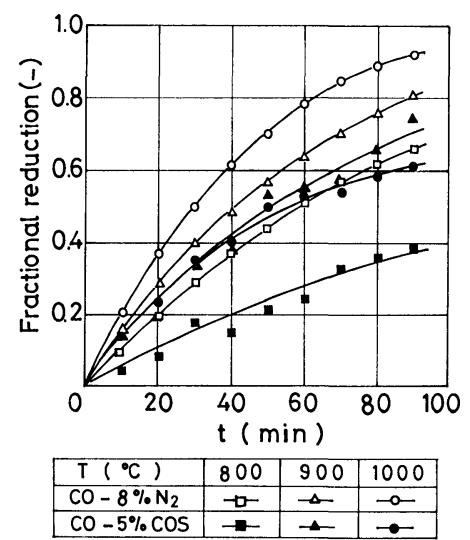

Fig. 6. Comparison of fractional reduction for 95\% CO$5 \% \mathrm{COS}$ simultaneous reaction with fractional reduction for $\mathrm{CO}-\mathrm{N}_{2}$ reduction under reduced $\mathrm{CO}$ partial pressure.

the reduction rate is controlled by the three steps. Intraparticle diffusivity $D_{e}$ and chemical reaction rate constant $k_{r}$ can be calculated from the values of the slope and the intercept of the straight line, respectively.

The resistance ratio for an estimate of the contribution of each of the three steps to the reduction rate is obtained as follows. The denominator of the right hand side of Eq. (1) expresses the resistances of the three steps, and the respective terms are the gas film resistance, the intraparticle diffusion resistance, and the chemical reaction resistance in the order from left to right. Hence, designating the each term as

$$
\begin{aligned}
R_{g} & =\frac{1}{k_{g}} \\
R_{D} & =\frac{1}{D_{e}} \frac{r_{o}\left(r_{o}-r_{i}\right)}{r_{i}} \\
R_{c} & =\frac{1}{k_{r}(1+1 / K)}\left(\frac{r_{o}}{r_{i}}\right)^{2}
\end{aligned}
$$

we obtain Eq. (3) as the overall resistance,

$$
R_{t}=R_{g}+R_{D}+R_{c}
$$

The each resistance ratio is then calculated from the ratio of the each resistance to the overall resistance.

\section{Results of Analysis}

Photograph 1 shows the cross sections of partially reacted pellets which were taken by interrupting the simultaneous reaction. Photograph 1(a) shows the cross sections after $60 \mathrm{~min}$ of the simultaneous reaction with $\mathrm{CO}-\mathrm{COS}$. FeS, metallic $\mathrm{Fe}$, and $\mathrm{FeO}$ layers are observed in this order from the outer side of the pellets inward, and the unreacted $\mathrm{Fe}_{2} \mathrm{O}_{3}$ is also observed in the central part of the pellet reacted at $800^{\circ} \mathrm{C}$. Photograph $1(\mathrm{~b})$ shows the cross sections after $30 \mathrm{~min}$ of the simultaneous reaction with $\mathrm{H}_{2}$ $\mathrm{H}_{2} \mathrm{~S}$. In this case, the cross sections show approximately the same appearance as those of the simultaneous reaction with $\mathrm{CO}-\mathrm{COS}$. As far as observed from those photographs, the reduction and the sulfi- 
a: $\operatorname{COS}-\mathrm{CO}(60 \mathrm{~min})$ b: $\mathrm{H}_{2} \mathrm{~S}-\mathrm{H}_{2}(30 \mathrm{~min})$

1: $800^{\circ} \mathrm{C} \quad$ 2: $900{ }^{\circ} \mathrm{C} \quad$ 3: $1000^{\circ} \mathrm{C}$

$\mathrm{S}$ : FeS, M: Metallic Fe, W: Wüstite,

$\mathrm{H}$ : Hematite

Photo. 1. Gross sections of partially reduced and sulfurized pellets.

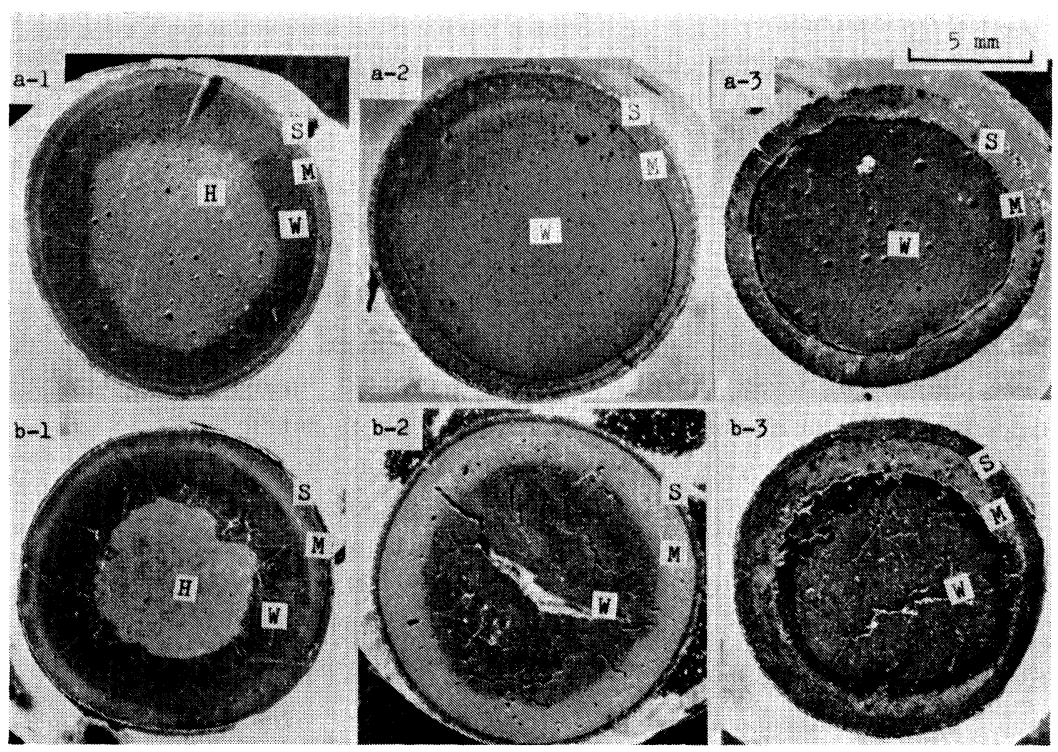

dation are found to proceed topochemically on different interfaces.

Accordingly, on the basis of the assumption that the reduction and the sulfidation took place on the different interfaces independently of each other, the apparent reaction rate constant $k_{r}$ and the intraparticle diffusion coefficient $D_{e}$ for the respective reaction were calculated by means of the method of analysis in mixed-control kinetics described above.

The rate parameters of the reduction for the simultaneous reaction are represented in Fig. 7 as Arrhenius-type plot together with the parameter for the reduction with pure reducing gases. If the reduction for the simultaneous reaction is compared with the reduction with pure reducing gases, both $k_{r}$ and $D_{e}$ of the former reaction are smaller than those of the latter reaction in all cases.

The rate constants $k_{r}$ of the reduction for the simultaneous reaction are 1/1.1 1/2.3 times as large as those for the reduction with pure reducing gases, and the temperature dependency also does not show any great difference between the two cases. (activation energy: $13 \sim 19 \mathrm{kcal} / \mathrm{mol}$ ) On the other hand, the intraparticle diffusion coefficient $D_{e}$ of the reduction for the simultaneous reaction with CO-COS is $1 / 2 \sim 1 / 6$ times as large as that for the $\mathrm{CO}$ reduction. $D_{e}$ for the reduction with $\mathrm{H}_{2}-\mathrm{H}_{2} \mathrm{~S}$ differed further greatly from that for $\mathrm{H}_{2}$ reduction. Moreover, the difference increased sharply as temperature is lowered, i.e., the ratio in $D_{e}$ was $1 / 5$ at $1000^{\circ} \mathrm{C}, 1 / 8$ at $900{ }^{\circ} \mathrm{C}$, and $1 /$ 60 at $800^{\circ} \mathrm{C}$, respectively, (activation energies are $13 \mathrm{kcal} / \mathrm{mol}$ for $\mathrm{H}_{2}$ reduction and $47 \mathrm{kcal} / \mathrm{mol}$ for $\mathrm{H}_{2-}$ $\mathrm{H}_{2} \mathrm{~S}$ reduction). The greater decrease of reduction rate at lower temperature, which was shown in Fig. 4 , is thought to be due to this difference of temperature dependency of $D_{e}$. Besides, $D_{e}$ for the reduction with $\mathrm{GO}-\mathrm{GOS}$ at $1000^{\circ} \mathrm{C}$ is smaller than that at $900{ }^{\circ} \mathrm{C}$ as shown in Fig. 7, which is thought to be responsible for the retardation of reduction for the simultaneous reaction shown in Fig. 4.

The resistance ratio at $900{ }^{\circ} \mathrm{C}$ calculated from the data of the present work are shown in Fig. 8. It is

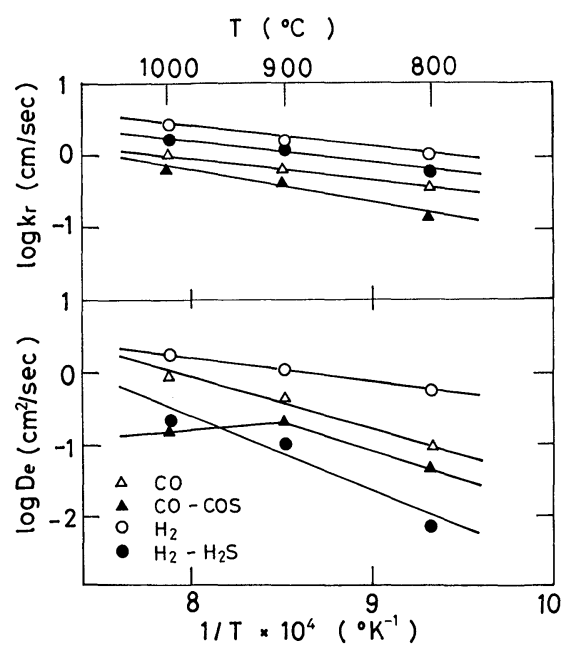

Fig. 7. Temperature dependence of the reduction rate parameters; $k_{r}$ and $D_{e}$.

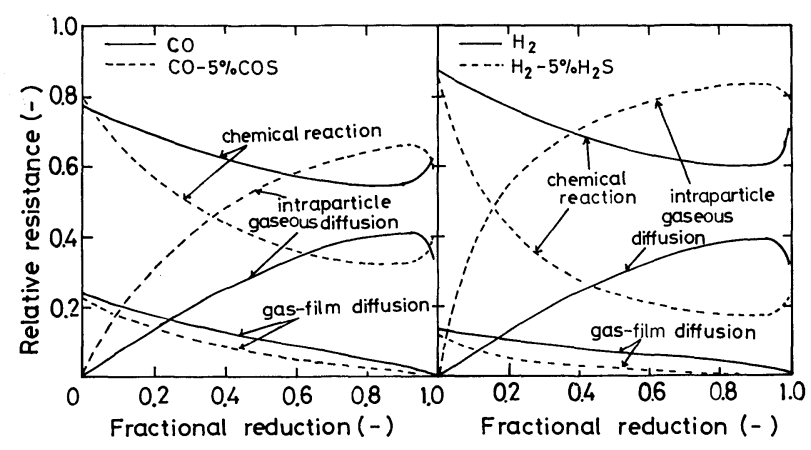

Fig. 8. Contributions of resistances to the overall resistance at $900^{\circ} \mathrm{G}$.

clear from this figure that the contribution of the intraparticle diffusion resistance to the reduction rate was increased remarkably by the addition of gaseous sulfide.

Although the parameters of the sulfidation were also obtained by the analysis of data for the simultaneous reaction, the results will be reported elsewhere in near future. 


\section{Observation of Structure}

The scanning electron micrographs of fractured surfaces of metallic iron layers after $\mathrm{CO}$ reduction and those of $\mathrm{FeS}$ layers after the simultaneous reaction with CO-5\% COS are shown in Photo. 2, and the similar fractographs of metallic iron layers after $\mathrm{H}_{2}$ reduction and those of $\mathrm{FeS}$ layers after the simultaneous reaction with $\mathrm{H}_{2}-5 \% \mathrm{H}_{2} \mathrm{~S}$ are shown in Photo. 3. These photographs show that the reduced iron layers are composed of porous structures and many micropores exist in the grains of metallic iron, while FeS layers are composed of dense structures having few micropores. If these fractured surfaces are observed in more detail, it is found that FeS layers are separated into two different layers, as shown in Photo. 4; the outer layer (FeS-I) consists of dense and large grains, and the inner layer (FeS-II) is composed of
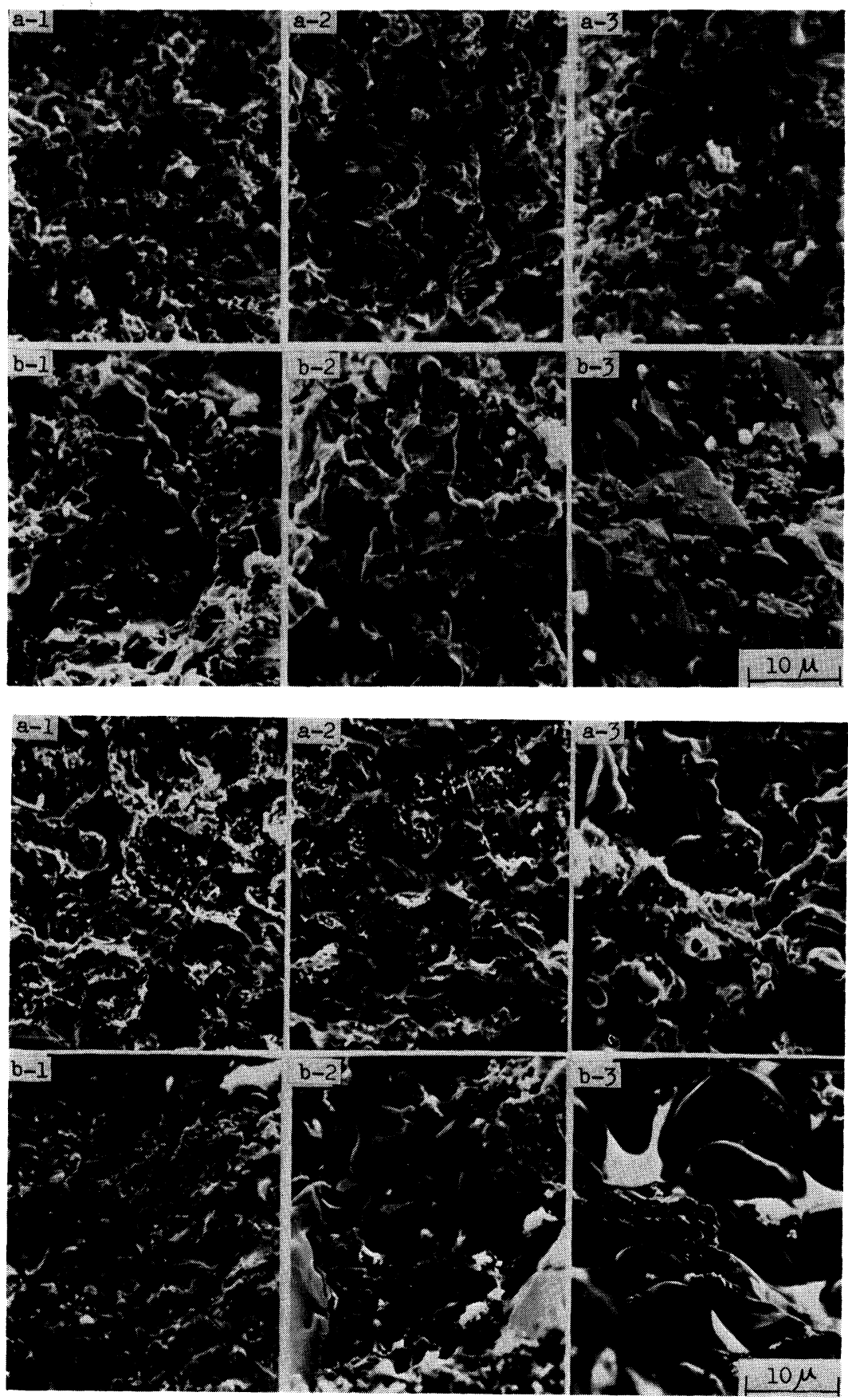

comparatively porous and fine grains. The FeS-I layer seems to have been formed from the recrystallization of the FeS-II layer, which had been produced by the sulfidation of the reduced iron as was men-

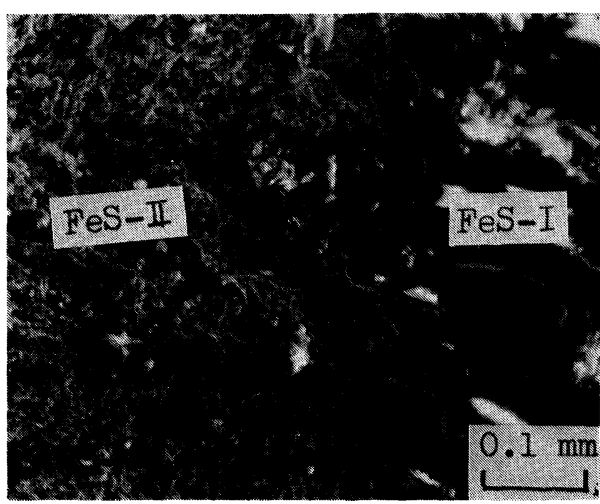

Photo. 4. Scanning electron micrograph of fracture surface of $\mathrm{FeS}$ layer after the simultaneous reaction at $800{ }^{\circ} \mathrm{C}$.

a: Metallic Fe, b: FeS

1: $800^{\circ} \mathrm{C}, \quad$ 2: $900{ }^{\circ} \mathrm{C}, \quad 3: 1000^{\circ} \mathrm{G}$ Photo. 2. Scanning electron micrographs of fracture surfaces of metallic Fe layers after the reduction with $\mathrm{CO}$ and $\mathrm{FeS}$ layers after the simultaneous reaction with $95 \% \mathrm{CO}-5 \% \mathrm{COS}$. a: Metallic Fe, b: FeS

1: $800{ }^{\circ} \mathrm{C}, \quad 2: \quad 900^{\circ} \mathrm{C}, \quad 3: \quad 1000^{\circ} \mathrm{C}$

Photo. 3. Scanning electron micrographs of fracture surfaces of metallic Fe layers after the reduction with $\mathrm{H}_{2}$ and $\mathrm{FeS}$ layers after the simultaneous reaction with $95 \% \mathrm{H}_{2}-5 \% \mathrm{H}_{2} \mathrm{~S}$. 
tioned in the previous papers. ${ }^{14,15)}$

In case of the simultaneous reaction, the results indicate that the dense FeS shells formed in the outer side of the pellets offered great resistance to the intraparticle diffusion of the gases, and that consequently the great decrease of the intraparticle diffusion coefficient was the largest cause of the retardation of reduction rate.

In the simultaneous reaction, however, because the reducing gas and the product gas diffuse through the three different layers of FeS-I, FeS-II, and M.Fe, the values of $D_{e}$ obtained from the reaction analysis may really be affected by many factors, so that it is difficult to discuss this problem quantitatively in the present conditions.

In the reduction for the simultaneous reaction with CO-COS, the value of $D_{e}$ at $1000^{\circ} \mathrm{C}$ is slightly smaller than that at $900^{\circ} \mathrm{C}$ as shown in Fig. 7, which suggests that the pores might very possibly be blocked up by the liquid produced in a part of the pellets in the period of reaction at $1000{ }^{\circ} \mathrm{C}$, because the eutectic temperatures for $\mathrm{Fe}-\mathrm{FeS}, \mathrm{FeO}-\mathrm{FeS}$, and $\mathrm{Fe}-\mathrm{FeO}-\mathrm{FeS}$ are $988{ }^{\circ} \mathrm{C}, 940{ }^{\circ} \mathrm{C}$, and $915^{\circ} \mathrm{C}$, respectively. However, any evidence of the formation of the liquid was not found in the cross section of the pellet after the reaction. It is necessary to investigate this subject experimentally in the future.

The reduction rate constant $k_{r}$ for the simultaneous reaction is also slightly smaller than that for the reduction with pure reducing gases as described above, which suggests that the gaseous sulfides were not completely consumed by the sulfidation on the $\mathrm{Fe}-\mathrm{FeS}$ interface, so that the gaseous sulfide which penetrated into the oxide core was responsible for the decrease of reduction rate. Photograph 5 shows the characteristic X-ray scanning images of $\mathrm{FeO}$ layer produced during the simultaneous reaction with $\mathrm{CO}-\mathrm{COS}$ taken by use of EPMA. A trace of sulfur is found in the FeO layer from the image, and in comparison with the reflex electron image with $\mathrm{S}-\mathrm{K}_{\alpha}$, the sulfur is observed to distribute especially in the neighborhood of the surface of the fine grains of $\mathrm{FeO}$. The microporous structure of the unreacted core of the pellets might possibly have varied by the slight sulfur penetrated. Photograph 6 shows the fractographs of $\mathrm{FeO}$ formed by $\mathrm{CO}$ reduction and by the simultaneous reaction with CO-COS, respectively. As compared with FeO layer formed by the reduction, the $\mathrm{FeO}$ layer by the simultaneous reaction is observed to consist of a roundish grains, which suggests that the surface area of the micropores taking part in the reduction was decreased to some extent by the trace of sulfur penetrated. The effects of gaseous sulfides on the structure of intermediate product layers during the reduction are an interesting subject for the future study.

\section{Summary}

Effects of addition of gaseous sulfides on the rate of reduction of iron oxide pellets were studied in the present work. The results are summarized as follows. The reduction rate was decreased very greatly by the addition of $\mathrm{COS}$ and $\mathrm{H}_{2} \mathrm{~S}$ to the reducing gases.

The effect of the decrease of partial pressure of the reducing gas by the addition of gaseous sulfides on the
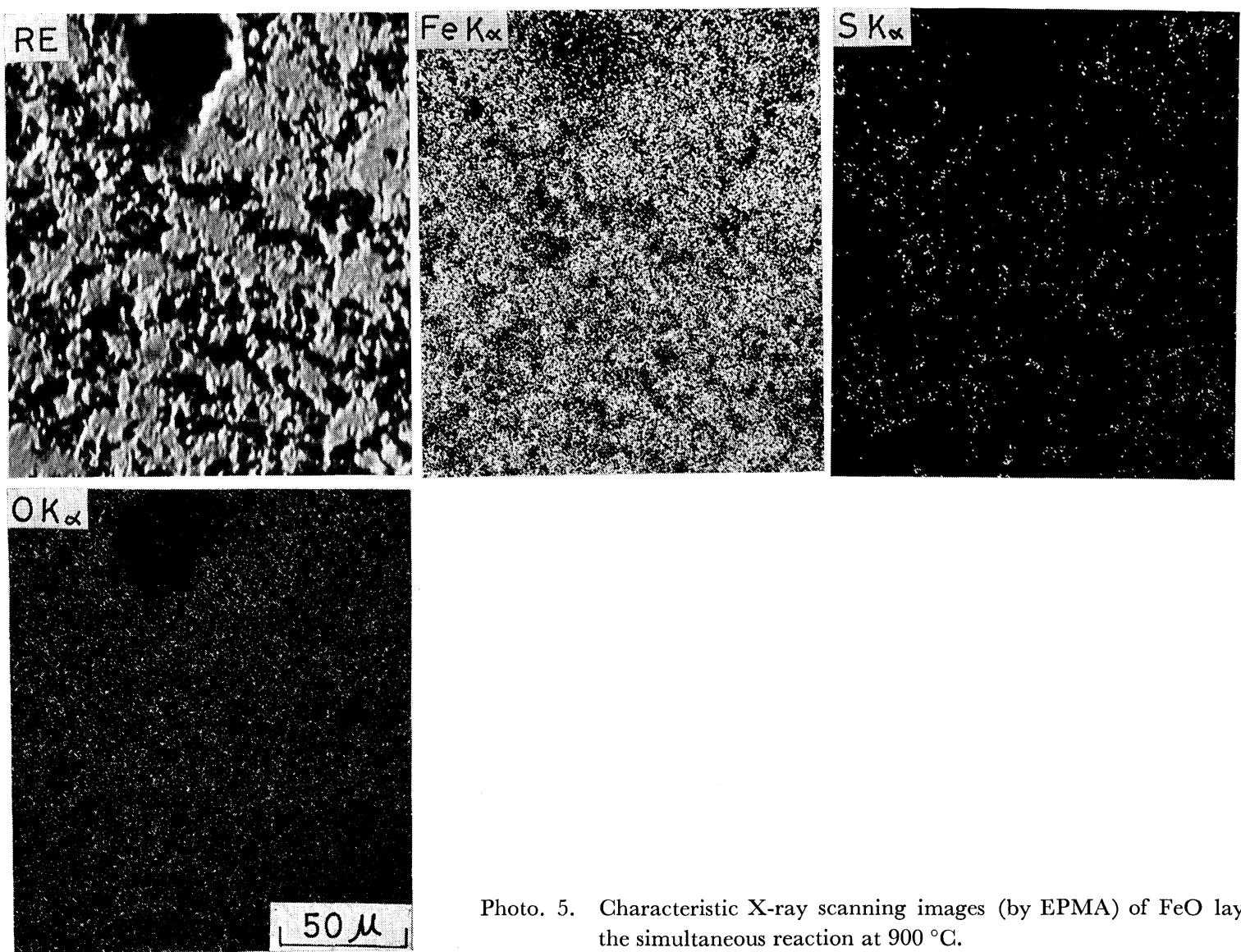

Photo. 5. Characteristic X-ray scanning images (by EPMA) of FeO layer after the simultaneous reaction at $900^{\circ} \mathrm{C}$. 


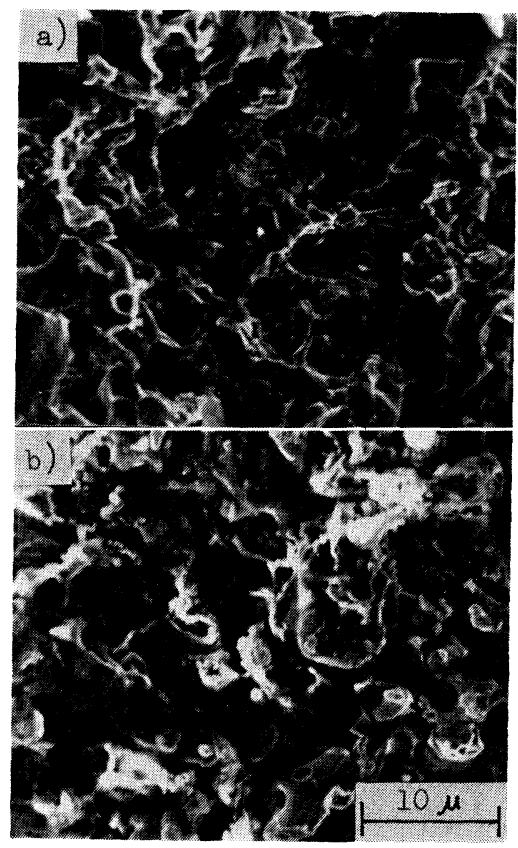

(a): Reduction, (b): Simultaneous reaction Temperature: $900{ }^{\circ} \mathrm{C}$

Photo. 6. Scanning electron micrographs of fracture surfaces of $\mathrm{FeO}$ layers after the reduction and the simultaneous reaction.

retardation of reduction rate is not significant.

The results from the reaction analysis and the observation of the fractured surface of the reacted pellets led to the conclusion that the retardation of the reduction rate of the iron oxide pellet was due to the formation of dense FeS shells in outer side of the pellets, which offered great resistance to the intraparticle diffusion of the reducing gas, in addition, that the reduction rate was also partially decreased by the trace of sulfur penetrated in the unreacted core which might possibly be concerned with the change of the microstructure of the unreacted layers.

As the sulfide content of reducing gas in the present work is much higher than that of blast furnace shaft gas, the investigation into the effects of sulfide gases on the reduction rate of iron oxide pellets in a blast furnace shaft is left to future study.

\section{Nomenclature}

$C_{A b}$ : concentration of reducing gas in bulk gas (mol/ $\mathrm{cm}^{3}$ )

$C_{A e}:$ equilibrium concentration of reducing gas ( $\mathrm{mol} /$ $\mathrm{cm}^{3}$ )

$D_{e}:$ intraparticle diffusion coefficient in the product layer $\left(\mathrm{cm}^{2} / \mathrm{s}\right)$

$d_{\mathrm{o}}:$ concentration of reducible oxide $\left(\mathrm{g}-\mathrm{atm} / \mathrm{cm}^{3}\right.$ )

$F:$ fractional reduction $(-)$

$f:$ relative thickness of product layer $(-)$

$K$ : equilibrium constant (-)

$k_{g}:$ gas film mass-transfer coefficient $(\mathrm{cm} / \mathrm{s})$

$k_{r}:$ apparent chemical reaction rate $(\mathrm{cm} / \mathrm{s})$

$\dot{n}: \quad$ over all reaction rate $(\mathrm{mol} / \mathrm{s})$

$r_{o}:$ pellet radius $(\mathrm{cm})$

$r_{i}:$ unreacted core radius $(\mathrm{cm})$

$t:$ reaction time (s)

$R_{t}: \quad$ overall resistance $(\mathrm{s} / \mathrm{cm})$

$R_{g}:$ gas film mass-transfer resistance $(\mathrm{s} / \mathrm{cm})$

$R_{D}$ : intraparticle diffusion resistance $(\mathrm{s} / \mathrm{cm})$

$R_{c}$ : chemical reaction resistance $(\mathrm{s} / \mathrm{cm})$

\section{REFERENCES}

1) V. H. Neuhaus, H.J. Langhammer, H. G. Geck and H. Schenck: Stahl u. Eisen, 85 (1965), 1578.

2) V. H. Neuhaus, H.J. Langhammer, H. G. Geck and H. Schenck: Arch. Eisenhüttenw., 37 (1966), 1.

3) W. L. Worrell and E. T. Turkdogan: Trans. AIME, 242 (1968), 1673.

4) G. Yoshii and Y. Mizukami: Tetsu-to-Hagané, 57 (1971), S371.

5) Y. Mizukami, K. Ishii and G. Yoshii: The 54th Committee (Ironmaking), the Japan Society for the Promotion of Science (JSPS), Rep. No. 1241, (1972).

6) H. Ueki, K. Ishii and G. Yoshii: Tetsu-to-Hagané, 59 (1973), A89.

7) N. Tsuchiya, M. Ohtani and K. Okabe: Tetsu-to-Hagané, 59 (1973), 33.

8) A.W.D. Hills: Process Engineering of Pyrometallurgy, ed. by M. J. Jones, Inst. Min. Metall., London, (1974), 81.

9) C. Yoshii, K. Ishii, S. Satoh and T. Konishi: Tetsu-toHagané, 61 (1975), S388.

10) C. Yoshii: "Fundamental Reactions in Blast Furnace", the 33rd and the 34th Nishiyama Memorial Lecture, ISIJ, (1975), 172.

11) H. Rausch, A. Saatçi, W. Thumm and F. Oeters: Stahl u. Eisen, 95 (1975), 1266

12) H. Rausch, A. Saatçi, W. Thumm and F. Oeters: Arch. Eisenhüttenw., 46 (1975), 623.

13) R. Takahashi, Y. Omori and Y. Takahashi: Tetsu-toHagané, 62 (1976), A99.

14) R. Kuwano and Y. Ono: Technology Reports of Kyushu Univ., 51 (1978), 701.

15) R. Kuwano and Y. Ono: Tetsu-to-Hagané, 64 (1978), 2101.

16) K. Nagata and P. Bolsaitis: Tetsu-to-Hagané, 65 (1979), S7; the 54th Committee (Ironmaking), the Japan Society for the Promotion of Science (JSPS), Rep. No. 1498, (1979).

17) T. Yagi and Y. Ono: Trans. ISIJ, 8 (1968), 377.

18) W. E. Ranz and M. R. Marshall: Chem. Eng. Prog., 48 (1952), 141 